\title{
THE EFFECT OF SERVICE EXPOSURE ON THE CREEP PROPERTIES OF CAST IN-738LC SUBJECTED TO LOW STRESS HIGH TEMPERATURE CREEP CONDITIONS
}

\author{
R. Castillo,* A.K. Koul** and J-P.A. Immarigeon** \\ *Product Reliability Department \\ Turbine and Generator Division \\ Westinghouse Canada Inc. \\ Hamilton, Ontario, Canada

\begin{abstract}
* Structures and Materials Laboratory
National Aeronautical Establishment

National Research Council of Canada

Ottawa, Ontario, Canada
\end{abstract}

\begin{abstract}
SUMMARY
Constant load ( $90 \mathrm{MPa}$ ) creep properties of specimens machined from new and service exposed JN-738I,C turbine blades are reported for testing temperatures in the range of 899 to $996^{\circ} \mathrm{C}$. The rupture lives in these tests varied between 250 to 10,000 hours.

There appears to be a transition temperature $\left(\sim 960^{\circ} \mathrm{C}\right)$ above and below which intragranular and grain boundary sliding deformation mechanisms predominate in IN-738LC at $90 \mathrm{MPa}$. Under intragranular deformation conditions, service exposed blades exhibit an increase in $\dot{\epsilon}_{\mathrm{m}}$ and $\epsilon_{\mathrm{r}}$ relative to new blades because the coarse $\gamma^{\prime}$ precipitates in service exposed blades facilitate flow. Under grain boundary sliding deformation conditions, however, the service exposed blades exhibit a decrease in $\dot{\epsilon}_{\mathrm{m}}$ and $\epsilon_{\mathrm{r}}$ relative to new blades because service induced break down of $M C$ carbides produces continuous networks of grain boundary $\mathrm{M}_{23} \mathrm{C}_{6}$ carbides which suppress the sliding more effectively during creep testing.

The rupture life in both new and service exposed blades appears to be governed by stress assisted environmental cracking rather than any deformation mechanisms 'per se.' Fracture in both materials occurs through the link-up of environmentally induced surface cracks with the creep induced internal cracks. Final fracture occurs by transgranular shear. The service exposed blades contain slightly lower $\mathrm{Cr}$ content in the grain boundary regions because of heavy $\mathrm{M}_{23} \mathrm{C}_{6}$ precipitation along the grain boundaries. It is suggested that the reduced oxidation resistance of the grain boundary regions in service exposed blades increases the severity of oxidation and results in marginally lower rupture lives during creep testing.
\end{abstract}


The effects of extended service times upon the mechanical properties of cast nickel base superalloy components in hot sections of gas turbine engines are not well understood. A series of time and stress dependent solid state precipitation reactions occur at service temperatures in these components that can adversely affect their structural integrity.(1)

Accelerated creep testing has generally been employed to demonstrate the effects of service exposure on mechanical properties, usually by conducting tests at stresses and temperatures higher than those experienced during service. The problem with this approach is that the deformation and fracture mechanisms during testing may be quite different from those prevailing under service conditions. In particular, the fracture mode can change from transgranular to intergranular as the deformation temperature is increased. (2) Such transition has also been observed in IN-738LC at constant creep testing temperature with changes in grain boundary microstructure.(3) Therefore, in order to analyze the effects of serviceexposure on the mechanical properties of hot parts, it is important to understand the microstructure property relationships during creep testing at near service stresses and temperatures.

This paper reports the results of a study on the relationship between microstructure and creep behaviour of conventionally cast IN 738LC, a nickel base superalloy, tested at a low stress and high tempcratures representative of approximate service conditions. The main purpose of the study was to provide information leading to the identification of the failure mechanism, which is the subject of some controversy for alloys of this type. (4) The investigation involved an evaluation of the microstructural changes caused by service and their influence on postexposure properties when compared to the material in the unexposed condition.

\section{Experimental Procedure}

The material selected for the study was obtained as precision cast turbine blades with nominal compositions as shown in Table I. Creep data were generated for one new blade and two used blades which had been in service for 14,000 and 31,000 hours respectively. The blade temperature in mid-airfoil section during service is known to be in the range of $830^{\circ} \mathrm{C}$ to $845^{\circ} \mathrm{C} .(3,5)$

All as-cast blades had been hot isostatically pressed (HIPed) at $1200^{\circ} \mathrm{C} / 2$ hours, ramp-cooled to $1120^{\circ} \mathrm{C}$ and then furnace cooled to room temperature. Post-HIP heat treatments included solutioning at $1120^{\circ} \mathrm{C} / 2$ hours followed by an air cool and aging at $845^{\circ} \mathrm{C} / 24$ hours followed by air cooling to room temperature. Microstructures of blades were evaluated by optical and scanning electron microscopy. The details of this evaluation are reported elsewhere. $(3,5)$ Creep tests were conducted in air, on TABLE I

\section{NOMINAL COMPOSITION IN WEIGHT \% OF COMMERCIAL CAST IN-738 LC ALLOY}

\begin{tabular}{|c|c|c|c|c|c|c|c|c|c|c|c|c|c|c|c|c|c|}
\hline $\begin{array}{l}\text { Material } \\
\text { Condition }\end{array}$ & C & Mo & $\mathrm{Cr}$ & $\mathbf{N i}$ & $\mathbf{w}$ & $\mathrm{Fe}$ & Co & Al & $\mathrm{Ti}$ & Nb & $\mathrm{Ta}$ & $\mathrm{Zr}$ & B & Mn & $\mathrm{Si}$ & $\mathbf{P}$ & $\mathrm{Cu}$ \\
\hline Unexposed & .10 & 1.74 & 16.01 & Bal. & 2.66 & .12 & 8.35 & 3.44 & 3.40 & .81 & 1.66 & .03 & .01 & $<.10$ & $<.10$ & $<.10$ & $<.10$ \\
\hline $\begin{array}{l}14,000 \mathrm{hr} \\
\text { Service }\end{array}$ & .09 & 1.77 & 16.03 & Bal. & 2.51 & .12 & 8.36 & 3.44 & 3.49 & .83 & 1.66 & .03 & .01 & $<.10$ & .03 & .005 & $<.05$ \\
\hline Service & .09 & 1.70 & 15.9 & Bal. & 2.59 & .10 & 8.29 & 3.37 & 3.36 & .70 & 1.64 & .04 & .01 & $<.10$ & $<.10$ & .004 & $<.10$ \\
\hline
\end{tabular}



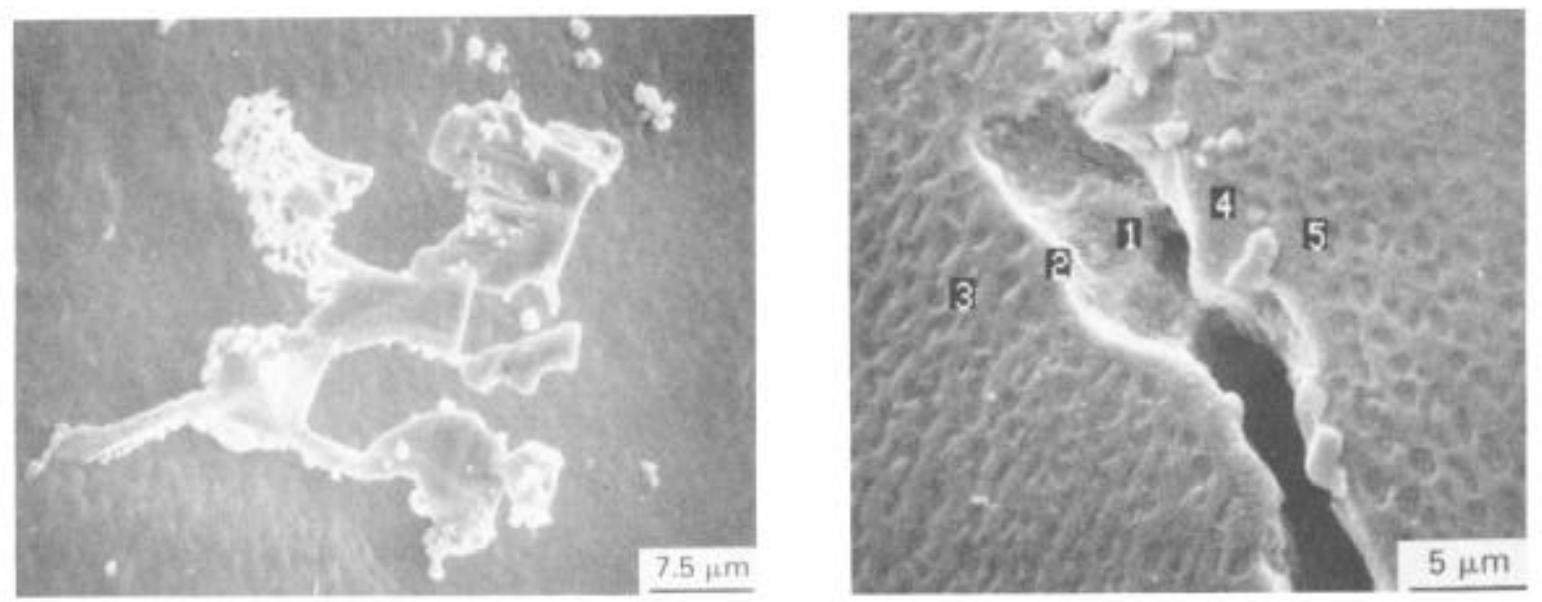

Fig. 1. Intragranular MC carbideFig. 2. Fractured grain boundary and $\mathrm{M}_{23} \mathrm{C}_{6}$ carbides attached to its surface as a result of its decomposition. area of a crept specimen. The $\mathrm{Cr}$ Concentration in spot nos. $1=9.63 \%, 2=$ $14.86 \%, \quad 3=15.12 \%, 4=$ $7.83 \%$ and $5=15.96 \%$ in wt. 9.

specimens machined from mid-airfoil sections of blades, in constant load creep machines at $90 \mathrm{MPa}$ and at temperatures between 899 and $996^{\circ} \mathrm{C}$. The creep specimens had a gage diameter of $4.0 \mathrm{~mm}$ and a gage length of $19.0 \mathrm{~mm}$. Creep strain was measured with an accuracy of greater than \pm 0.01 pct by means of a linear variable displacement transducer (LVDT).

\section{Results}

Previous studies have indicated that $\gamma^{\prime}$ precipitates coarsen and MC carbides degenerate in these blades during service.(3,5) Primary MC carbides break down into $\mathrm{M}_{23} \mathrm{C}_{6}$ carbides which precipitate preferentially along grain boundaries, thus modifying the original grain boundary microstructure. Evidence of MC carbide degeneration is shown in Fig. 1. Free carbon released by MC carbide decomposition diffuses rapidly to the grain boundaries, reacting with surrounding $\mathrm{Cr}$ to form $\mathrm{M}_{23} \mathrm{C}_{6}$ carbides, with the result that the grain boundary regions are depleted in $\mathrm{Cr}$, Fig. 2 . Since $\mathrm{Cr}$ is the key element responsible for the corrosion resistance of the alloy, the reduction in $\mathrm{Cr}$ content close to the grain boundaries increases the susceptibility of the material to intergranular oxidation.

In both new and service exposed materials, several types of MC carbides were detected that were rich in the usual carbide forming elements, namely, $\mathrm{Ti}, \mathrm{Nb}$ and $\mathrm{Ta}$. Approximate compositions of the four types of MC carbides that were identified are given in Table II.

TABLE II

METALLIC ELEMENT COMPOSITION (in wt. pct.) OF INTRAGRANULAR MC CARBIDES

$\begin{array}{lllllll} & \text { Ta } & \text { Nb } & \text { Ti } & \text { Cr } & \text { Co } & \text { Ni } \\ M_{C} & 47.0 & 19.0 & 30.0 & 1.4 & 1.6 & 3.0 \\ M_{\text {i }} & 28.0 & 31.0 & 30.0 & 2.0 & 1.3 & 7.9 \\ M_{\text {III }} & 15.0 & 6.5 & 75.0 & 1.2 & & 2.0 \\ M_{\text {IV }} & 26.0 & 11.0 & 58.0 & 1.6 & & 3.0\end{array}$




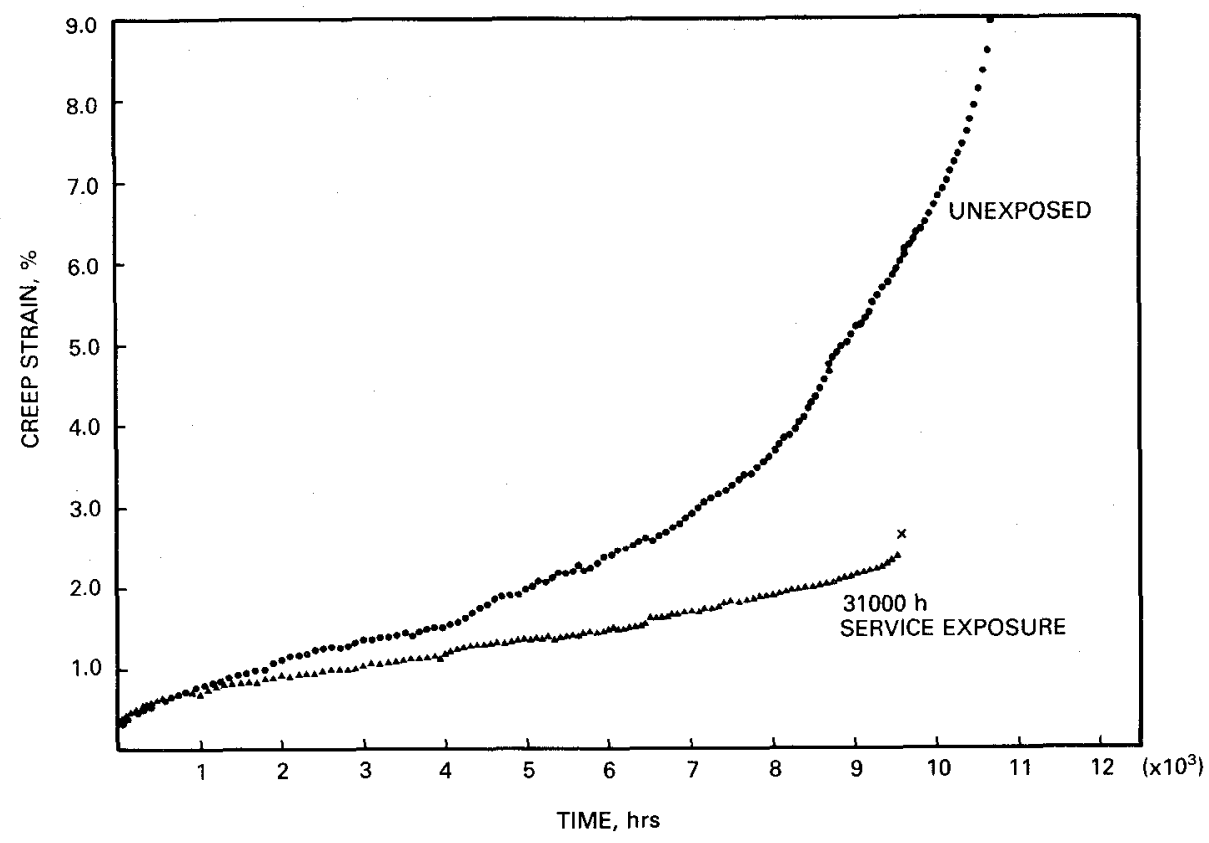

(a)

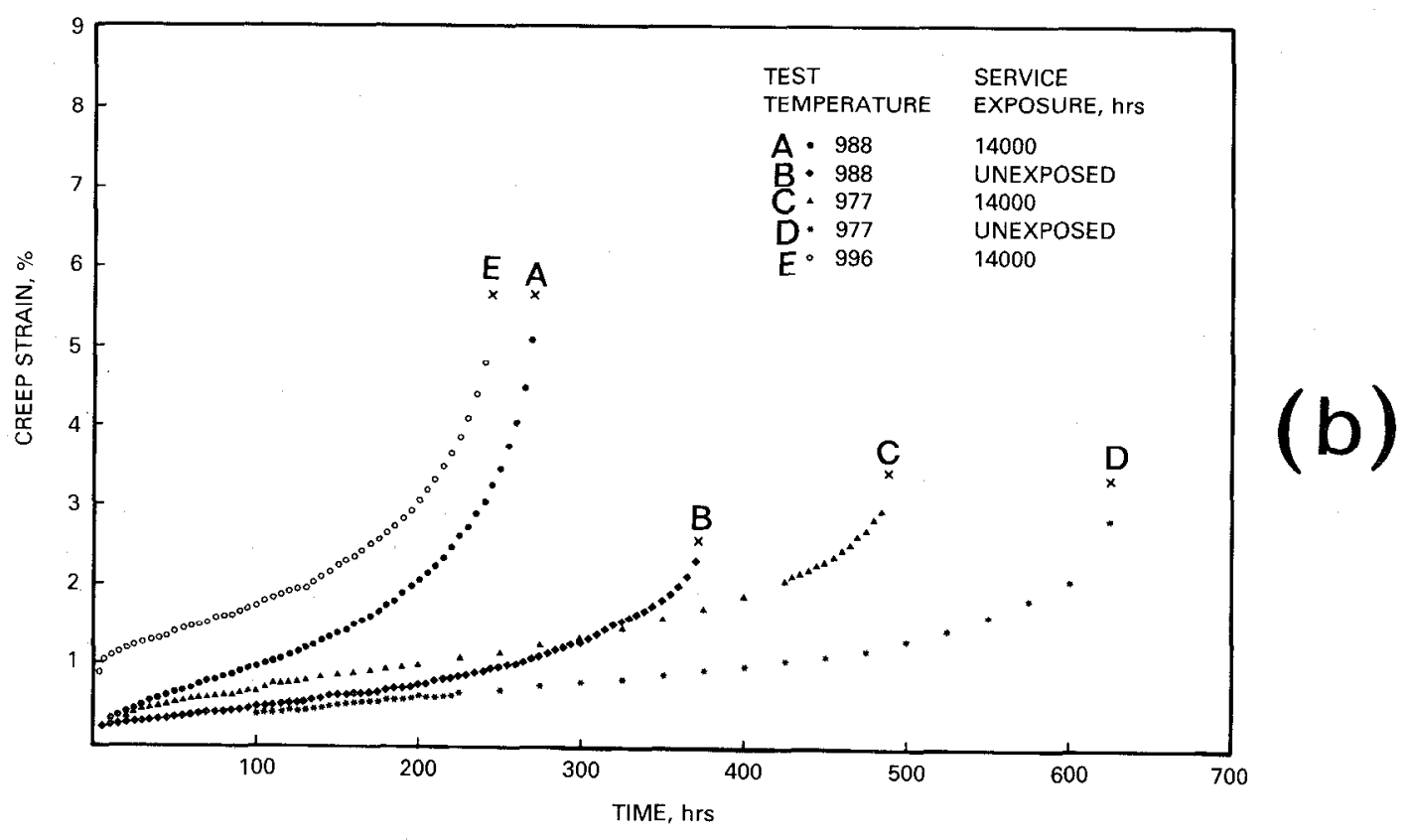

Fig. 3 Effect of service exposure on the creep behaviour of new and service exposed IN-738LC blades tested at $90 \mathrm{MPa}$ and (a) $899^{\circ} \mathrm{C}$ and (b) 977,988 and $996^{\circ} \mathrm{C}$.

\section{Creep testing Results}

Creep curves for long term (low temperature) and short term (high temperature) testing conditions are shown in Figs. $3 \mathrm{a}$ and $3 \mathrm{~b}$ respectively. The data indicate that compared to new blades higher creep rates prevail during short term tests in service-exposed material whereas the reverse is observed during long term tests of the order of 2,000 to 10,000 hours. 


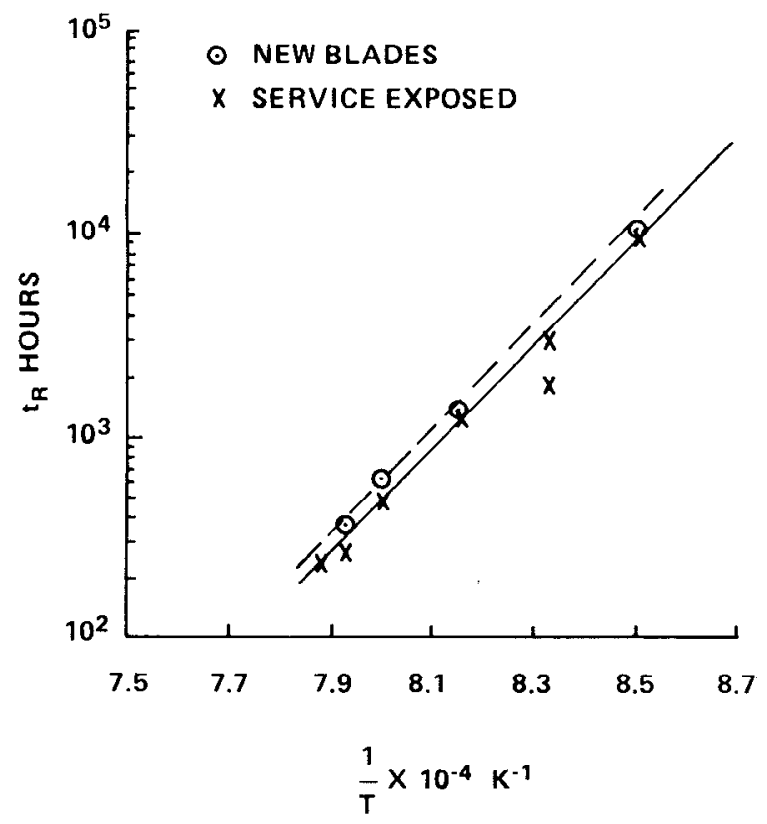

Fig. 4 Effect of creep testing Fig. 5 temperature on $t_{r}$ of new and service exposed blades at $90 \mathrm{MPa}$.

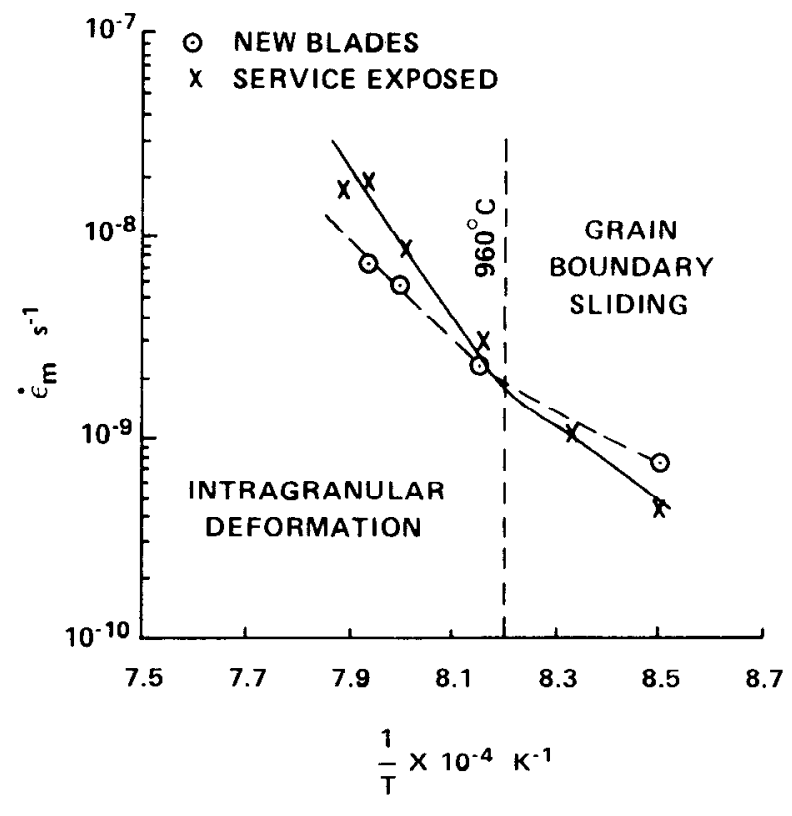

Effect of creep testing temperature on $\dot{\epsilon}_{\mathrm{m}}$ of new and service exposed blades at $90 \mathrm{MPa}$.

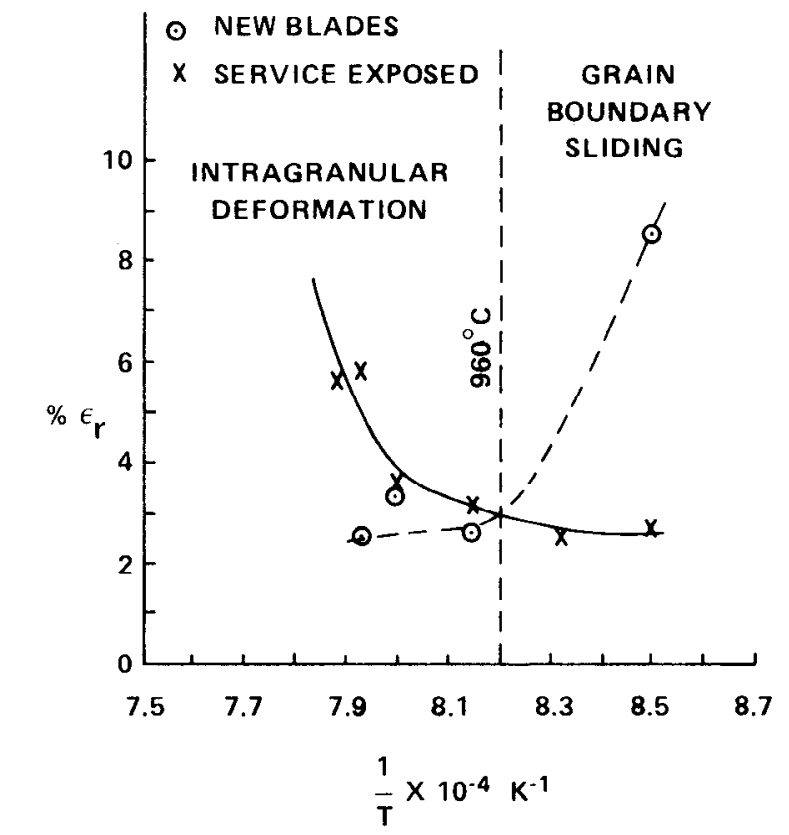

Fig. 6 Effect of creep testing temperature on $\epsilon_{\mathrm{r}}$ of new and service exposed blades at $90 \mathrm{MPa}$.

The effects of service-exposure on rupture life, $t_{r}$, minimum creep rate, $\dot{\epsilon}_{\mathrm{m}}$, and creep ductility, $\epsilon_{\mathrm{r}}$, for all test conditions examined can be seen in Figures 4,5 and 6 , respectively. Under comparable testing conditions, the service-exposed material exhibited rupture lives that were marginally lower than those for the new material, Figure 4. However, there were noticeable differcnces in $\dot{\epsilon}_{\mathrm{m}}$ and $\epsilon_{\mathrm{r}}$ that varied in magnitude with test temperature. Below approximately $960^{\circ} \mathrm{C}$, the service-exposed material exhibited lower $\dot{\epsilon}_{\mathrm{m}}$ values whereas above this temperature, its $\dot{\epsilon}_{\mathrm{m}}$ was higher, Fig. 5. Similarly, compared to new blades $\epsilon_{\mathrm{r}}$ for service exposed 
material was lower below $960^{\circ} \mathrm{C}$ and higher above this temperature, Fig. 6 . It thus appears that $960^{\circ} \mathrm{C}$ is a transition temperature above and below which different deformation mechanisms operate leading to differences in $\dot{\epsilon}_{\mathrm{m}}$ and $\epsilon_{\mathrm{r}}$ between the new and service-exposed material.

\section{Microstructures of Crept Specimens}

There was eviclence of enhanced $\gamma^{\prime}$ coarsening and rafting near the grain boundaries in specimens tested at lower temperatures in long term tests, Fig. 7. This indicates that flow localization occurs in regions adjacent to the grain boundaries and may be viewed as an accommodation to grain boundary sliding. There was also some evidence of $\gamma^{\prime}$ rafting in short term tests at high test temperatures, Fig. 8, although the $\gamma^{\prime}$ coarsening was minimal in this case. These observations suggest that grain boundary sliding predominates at lower test temperatures whereas intragranular deformation predominates at higher test temperatures below and above the $960^{\circ} \mathrm{C}$ transition, Figs. 5 and 6.

After creep testing at lower temperatures, under near service conditions, iron rich areas were observed along the grain boundaries of the new material Fig. 9. It is not clear what role these Fe-rich areas play in the creep behaviour of Ni-base superalloys.

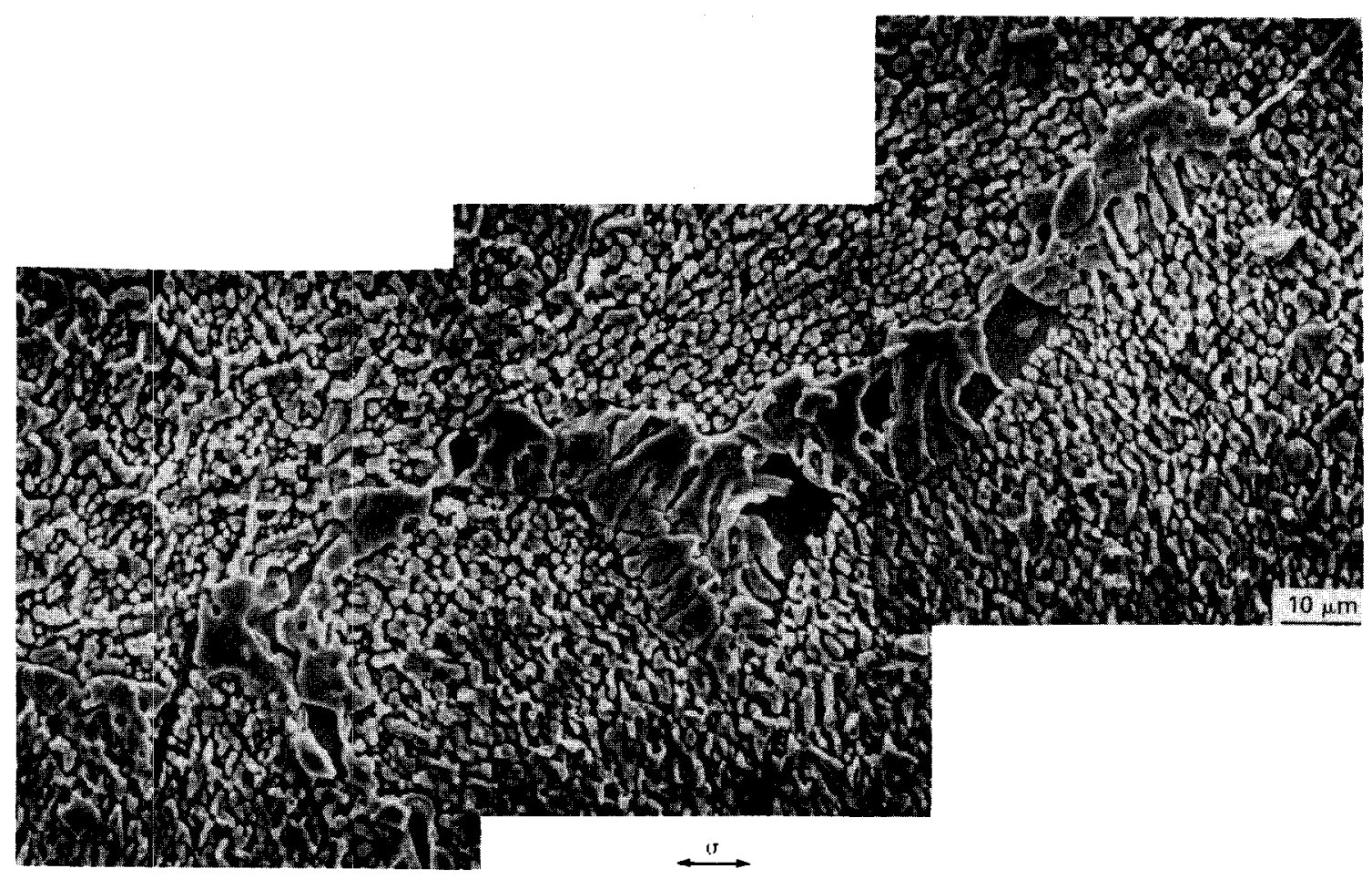

Fig. 7 Typical grain boundary structure of the new blade specimen creep tested at a lower temperature $\left(899^{\circ} \mathrm{C}\right)$ at $90 \mathrm{MPa}$ showing grain boundary $\gamma^{\prime}$ coarsening and rafting .

Fracture Behaviour of Crept Specimens

All specimens tested to rupture contained cavities and cracks at grain boundaries and oxidized surface cracks at intergranular sites, Fig. 10. In all cases, surface grain boundary cracks were larger than internal cracks and were mostly normal to the tensile stress axis. Intragranular /interdendritic fracture features were observed in both new and service exposed materials up to approximately one-half of the specimen gage section, Fig. 10. The fast fracture areas showed the appearance of typical transgranular shear inclined at about $45^{\circ}$ to the specimen axis, Fig. 10. 




Fig. 8 Some $\gamma^{\prime}$ rafting in new
blade specimen
tested at $977^{\circ} \mathrm{C}$ and 90
MPa.

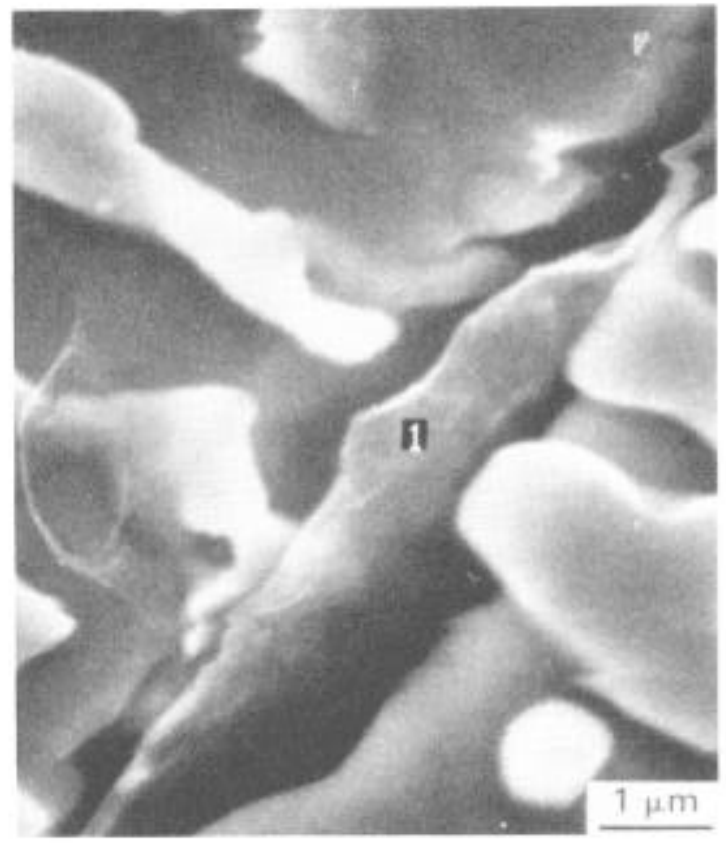
Fig. 9 Example of an $\mathrm{Fe}$ rich region in a new blade sample creep tested at $899^{\circ} \mathrm{C}$ and $90 \mathrm{MPa}$. In spot No. $1 \mathrm{Fe}=4.18$ wt.\% and in the matrix $\mathrm{Fe}=0.12$ wt.\%.

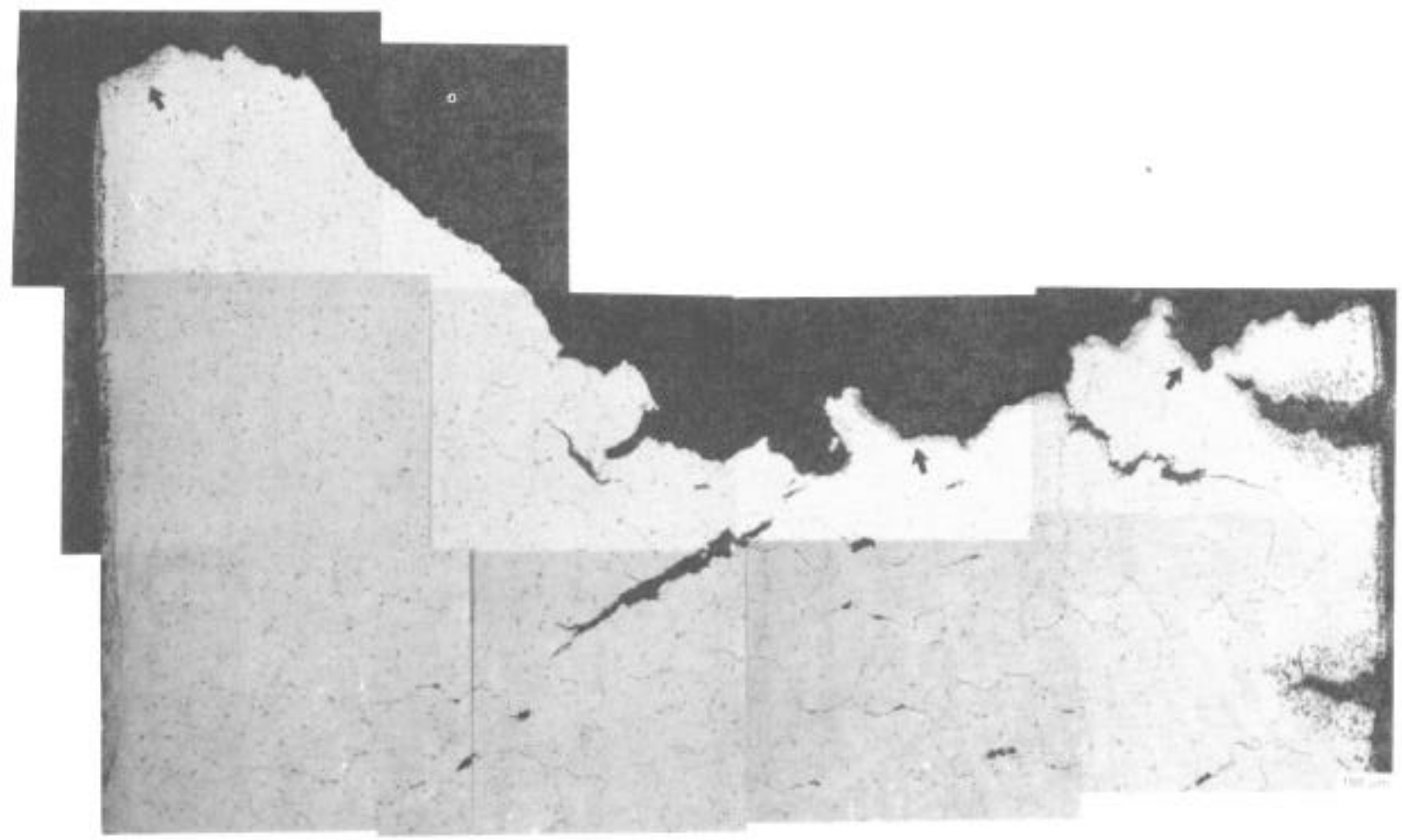

Fig. 10 Optical micrograph showing evidence of intergranular oxide penetration (arrows), micro-cracking and transgranular shear. 


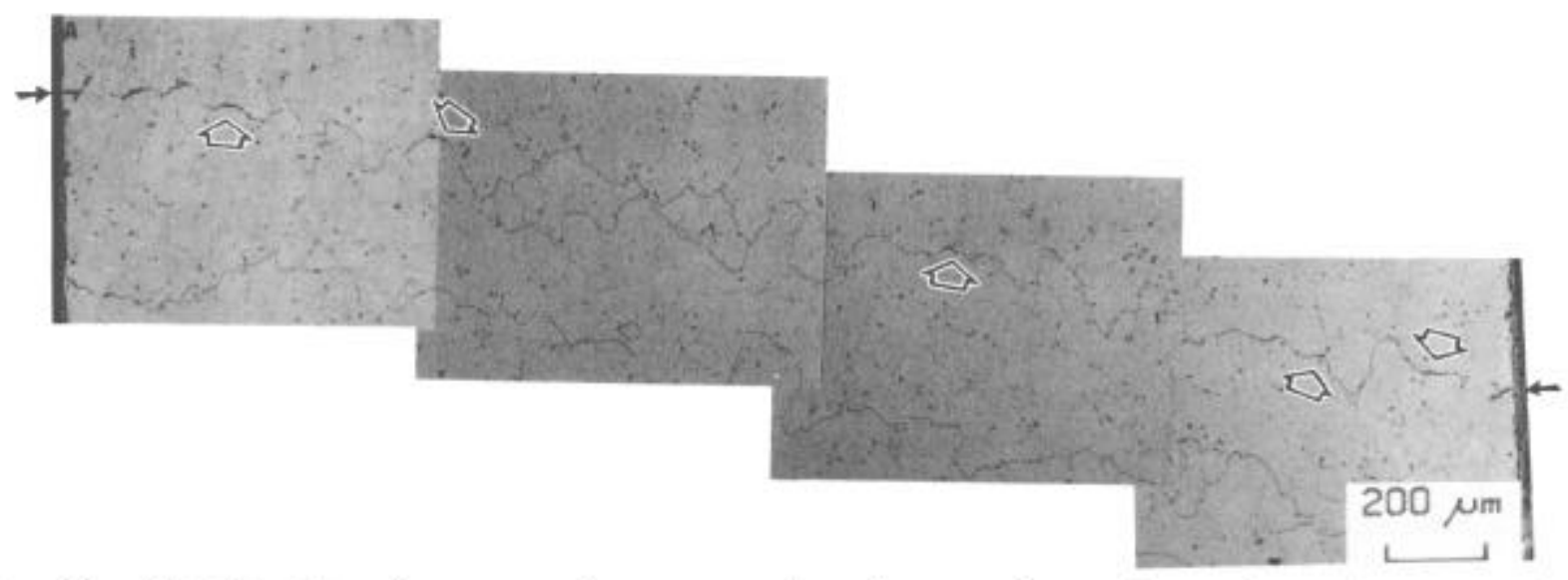

Fig. 11 Grain boundary surface cracks (arrows) and early stages of internal crack link-up (open arrows) in a service exposed specimen creep tested at $927^{\circ} \mathrm{C}$ and interrupted during early stages of secondary creep.

Damage in the gage length of the crept specimens showed important differences between the new and service exposed specimens that were creep tested at temperatures below $960^{\circ} \mathrm{C}$. The $899^{\circ} \mathrm{C}$ creep tests indicated that the new material contained relatively more creep cavities than the service exposed material under identical creep loading conditions. Internal cracking was also more extensive in the new material than the service exposed material. These observations suggest that below $960^{\circ} \mathrm{C}$ the continuous networks of grain boundary $\mathrm{M}_{23} \mathrm{C}_{6}$ carbides in the service exposed material suppress deformation in the grain boundary regions. At creep testing temperatures above $960^{\circ} \mathrm{C}$, however, the differences in the fracture behaviour of the new and service exposed specimens were less obvious.

Interrupted creep tests indicated that environmentally assisted intergranular cracking occurs early during secondary creep in both new and service exposed materials, Fig. 11, and concurrently the internal grain boundary cracking also occurs within the bulk of the material. Final fracture appears to take place through the link up of the surface crack with the internal cracks in all cases, Figs. 10 and 11.

\section{Discussion}

The results indicate that there is a transition in the predominant deformation mechanism as the creep testing temperature decreases. At 90 $\mathrm{MPa}$, the transition occurs around $960^{\circ} \mathrm{C}$ in the alloy investigated, Figs. 5 and 6 . The activation energies (Q) for the deformation processes, below and above the transition temperature, were calculated based on power law fits through the data of the form:

$$
\dot{\epsilon}_{\mathrm{m}}=\mathrm{A} \mathrm{e}^{-Q / R T} \boldsymbol{\sigma}
$$$$
\text { ............. (1) }
$$

where $\sigma$ is the applied stress, $Q$ is the activation energy, $T$ is the test temperature, $\mathrm{R}$ is the gas constant and $\mathrm{A}$ and $\mathrm{n}$ are material constants. Below $960^{\circ} \mathrm{C}$ the $Q$ values were of the order of $16-22 \mathrm{KCal} / \mathrm{mole}$ whereas above the transition temperature they were approximately $30-40 \mathrm{KCal} / \mathrm{mole}$ for both new and service exposed materials. While the $Q$ values below and above the transition temperature do not match the activation energy values for grain boundary or volume diffusion of various alloying additions in Ni, it is significant that below $960^{\circ} \mathrm{C}$ the $Q$ values are roughly one half the value observed above $960^{\circ} \mathrm{C}$. The deviation in the actual magnitude of $Q$ from that reported for intragranular and grain boundary sliding deformation mechanisms is not totally unexpected. The true $Q$ values for a given deformation mechanism can only be obtained providing the structure is kept 
constant, a condition that cannot be satisfied in metastable Ni-base alloy systems. However, in view of the evidence for flow localization adjacent to the grain boundaries, (Fig. 7), the crossover in $\dot{\epsilon}_{\mathrm{m}}$, (Fig. 5) and the smaller $Q$ values below the transition temperature it can be argued that grain boundary sliding predominates below $960^{\circ} \mathrm{C}$ whereas intragranular flow predominates above $960^{\circ} \mathrm{C}$.

The differences in the overall creep behaviour of new and service exposed blades can be rationalized in terms of the differences in the intragranular and grain boundary microstructural features of the two materials. Above $960^{\circ} \mathrm{C}$, the intragranular deformation mechanism predominates and the service exposed blades are expected to show an increase in $\dot{\epsilon}_{\mathrm{m}}$, and $\epsilon_{\mathrm{r}}$, Figs. 5 and 6 , because they contain coarse $\gamma^{\prime}$ precipitates which lower the grain strength. In contrast, below $960^{\circ} \mathrm{C}$, the grain boundary sliding mechanism predominates and the service exposed blades would be expected to show lower $\dot{\epsilon}_{\mathrm{m}}$ and $\epsilon_{\mathrm{r}}$ values, Figs. 5 and 6 , because continuous carbide networks in service exposed blades will suppress the grain boundary sliding more effectively.

The similar $t_{r}$ values of the new and service exposed material at comparable testing temperatures can be attributed to the fact that stress and environment assisted crack nucleation and propagation controls $t_{r}$ rather than a specific deformation mechanism 'per se'. For both materials final fracture occurs in air as a consequence of the propagation of one or several of the surface initiated cracks nucleated early during the secondary stage of creep. Fig. 10 shows the profile of a crack, which was able to follow the transverse grain boundary to a greater depth causing final fracture. Oxides and nitrides were observed around the crack surface. Similar surface nucleated cracks, located in the specimen shoulder section, showed minimal grain boundary oxidation. Clearly, the rate of oxygen penetration along the grain boundaries is greatly enhanced by applied stress. The manner in which oxygen prompts grain boundary embrittlement leading to intergranular failures could be explained by a mechanism originally proposed by Briknell and Woodford.(6) Initially, the boundary is embrittled by oxygen penetration in the near surface region. This embrittled boundary fails afterwards in tension and the free surfaces thus produced are oxidized while oxygen diffuses down the boundary ahead of the crack. It appears that oxygen penetration along grain boundarics indeed precedes actual crack formation. The metallographic evidence suggests that the extremely low $\mathrm{Cr}$ content in the boundary regions plays some role during fracture because of the reduced oxidation resistance of the grain boundaries. The marginally lower $t_{r}$ values of the service exposed blades are perhaps related to this effect, Fig. 4.

\section{Conclusions}

The results demonstrate that short term creep testing does not reveal loss of creep ductility due to grain boundary embrittlement in service exposed blades. This is because intragranular deformation mechanisms are dominant during short term testing whereas grain boundary sliding predominates under service conditions.

\section{References}

1. J.W. Martin and R.D. Doherty, "Stability of Microstructure in Metallic Systems," (University Press: Cambridge, 1976). 
2. H.R. Tipler et. al, Proc. Conf. "High Temperature Alloys for Gas Turbines," Liege, Belgium, September 25-27, 1978, Applied Science Pub., 359-407

3. R. Castillo and A.K. Koul, Proc. Conf. "High Temperature Alloys for Gas Turbines and Other Applications," Liege, Belgium, October 6-9, 1986, p. 1395-1410.

4. S. Ogersby and T.B. Gibbons, "Creep Cavitation in Cast $\mathrm{Ni}-\mathrm{Cr}$ Base Alloy," J. Mat. Sci and Eng., 59 (1983), L11-L 14

5. A.K. Koul and R. Castillo, "Assessment of Microstructural Damage and Its Rejuvenation in Turbine Blades," Met. Trans. A, In Press, 1988.

6. R.H. Briknell and D.A. Woodford, "Grain Boundary Embrittlement of the Fe-Base Superalloy IN-903," Met. Trans A., 12 (1981) 1673-1680. 